\title{
Preparation of cobalt titanates via co-precipitation while using industrial intermediates as titanium precursors
}

\author{
Aleksander Przepiera, Justyna Płaska, Krystyna Przepiera, Maciej Jabłoński, \\ Aleksandra Konratowska
}

West Pomeranian University of Technology, Szczecin, Institute of Chemistry and Environmental Protection, al. Piastów 42, 71-065 Szczecin, Poland, e-mail: aleks@zut.edu.pl

\begin{abstract}
This paper reports on the results of cobalt titanates preparation by calcination of green bodies obtained by a co-precipitation method. For the investigations were used: as titanium sources, acidic solutions of titanyl sulfate and hydrous titanium dioxide, originating from the production process of titanium dioxide by sulfate method. The composition of the obtained materials was determined using titration methods. The calcined powders were characterized by X-ray diffraction method. It has been found that the obtained products are composed of cobalt methatitanate $\mathrm{CoTiO}_{3}$ or cobalt orthotitanate $\mathrm{Co}_{2} \mathrm{TiO}_{4}$ occurring as single phases, and also as cobalt titanates and titanium dioxide phase mixtures. The proposed method of proceeding can be used for the preparation of series of transition metals titanates, such as nickel, iron, zinc, copper and also aluminium titanates.
\end{abstract}

Keywords: titanium compounds, cobalt titanates preparation, titanyl sulfate, hydrous titanium dioxide.

\section{INTRODUCTION}

Cobalt titanates are known as useful materials because of the possibility of their technical application as green pigments, catalysts or in electric devices. Three cobalt titanates are known. They are the following: cobalt methatitanate, $\mathrm{CoTiO}_{3}$, having the ilmenite structure, cobalt orthotitanate, $\mathrm{Co}_{2} \mathrm{TiO}_{4}$, with inverse spinel structure, and pseudobrookite-type cobalt dititanate, $\mathrm{CoTi}_{2} \mathrm{O}_{5}{ }^{1}$. Among them $\mathrm{CoTiO}_{3}$ is considered as the most important cobalt titanate due to its high thermal stability, even at temperatures above $1000^{\circ} \mathrm{C}$, weak magnetism, semiconductivity, acousto-optic and electro-optic properties and high dielectric constant value of approximately $40^{2-4}$. Therefore, $\mathrm{CoTiO}_{3}$ can be used, for example, as semiconducting device ${ }^{2}$, hydrocarbonate catalyzer ${ }^{3}$, gas sensing material ${ }^{5-7}$ or pigment ${ }^{8}$.

There are known several methods for the preparation of cobalt titanates. The most popular is a solid-state reaction between titanium dioxide or hydrous titanium dioxide and cobalt oxide, hydroxide, or carbonate ${ }^{9}$. Although this method needs high temperature, about $1000^{\circ} \mathrm{C}$, and long time, about 10 hours, small amounts of unreacted initial compounds can be expected ${ }^{10}$. Therefore, the methods based on the synthesis in the solution phase, like precipitation ${ }^{11}$, sol-gel ${ }^{2}$, or Pechini process ${ }^{12}$, providing suitable mixing of the reagents, have recently been studied intensively.

This work reports on the preparation of cobalt titanates by the co-precipitation method, using solutions of $\mathrm{TiOSO}_{4}$ or $\mathrm{TiO}_{2} \cdot \mathrm{nH}_{2} \mathrm{O}$ as titanium sources, $\mathrm{CoSO}_{4}$ as cobalt source, $\mathrm{H}_{2} \mathrm{O}_{2}$ as a complexing agent, and $\mathrm{NaOH}$ as a precipitating agent. This approach is based on adding $\mathrm{H}_{2} \mathrm{O}_{2}$ to the acidic solution containing titanyl ion $\mathrm{TiO}^{2+}$, in order to obtain titanium complex ion, $\left[\mathrm{TiO}\left(\mathrm{H}_{2} \mathrm{O}_{2}\right)\right]^{2+}$. Complex ion of cobalt $\left[\mathrm{Co}\left(\mathrm{H}_{2} \mathrm{O}\right)_{6}\right]^{2+}$ can be easily prepared by dissolving of cobalt sulfate in water. The proceeding of the reaction between these two ions possessing the same charge requires the presence of $\mathrm{OH}^{-}$ions, which were introduced with $\mathrm{NaOH}$ aqueous solution. With the gradual increasing of $\mathrm{pH}$, as a result of $\mathrm{NaOH}$ dropping to the starting solution, the formation of green precipitate took place. The principal advantage of this method is the short time of the co-precipitation process, $(0.5-1 \mathrm{~h})$, and the possibility of carrying out the process at room temperature. However, higher temperature is preferred to achieve quick sedimentation of the product.

The used titanyl sulfate solution and hydrous titanium dioxide paste were the intermediate products from the sulfate process of titanium dioxide production, as shown on the scheme in Figure 19,13 . The raw material in this process is ilmenite, $\mathrm{FeTiO}_{3}$. As a result of decomposition of ilmenite by sulfuric acid the titanyl sulfate solution is obtained, according to the following equation ${ }^{\mathbf{1 4}}$ :

$\mathrm{FeTiO}_{3(\mathrm{~s})}+2 \mathrm{H}_{2} \mathrm{SO}_{4(\mathrm{aq})} \rightarrow \mathrm{TiOSO}_{4(\mathrm{aq})}+\mathrm{FeSO}_{4(\mathrm{aq})}+$ $2 \mathrm{H}_{2} \mathrm{O}_{(1)}$

The prepared solution of a brownish black color is cooled in order to remove iron sulfate by crystallization. Then the purified and concentrated titanium sulfate solution is subjected to hydrolysis and the precipitation of colloidal titanium dioxide occurs by the following equation':

$\mathrm{TiOSO}_{4(\mathrm{aq})}+2 \mathrm{H}_{2} \mathrm{O}_{(\mathrm{l})} \rightarrow \mathrm{TiO}_{2} \cdot \mathrm{H}_{2} \mathrm{O}_{(\mathrm{s})}(\downarrow)+\mathrm{H}_{2} \mathrm{SO}_{4(\mathrm{aq})}$

Both the intermediate products originating from titanium dioxide manufacture are unstable regarding the time. In the titanyl sulfate solution the precipitation of hydrous titanium dioxide occurs, which results in decreasing of titanium content. The concentration of iron, whose small amounts remain after iron sulfate crystallization, also varies with time because it can be adsorbed on active surface of hydrous titanium dioxide precipitate. In addition, as the titanyl sulfate solution is stored, the oxidation state of iron is partially changing from $\mathrm{Fe}^{2+}$ to $\mathrm{Fe}^{3+}$. During the storage of the hydrous titanium dioxide, decreasing of its hydration degree and increasing of titanium content takes place. Therefore, using $\mathrm{TiOSO}_{4}$ and $\mathrm{TiO}_{2} \cdot \mathrm{nH}_{2} \mathrm{O}$, as the starting materials to prepare other titanium compounds, needs control of titanium and iron concentration.

The aim of our investigations was the elaboration of cobalt titanates preparation method by co-precipitation from solution using, as raw materials, titanyl sulfate solu- 
tion $\mathrm{TiOSO}_{4}$, and hydrous titanium dioxide $\mathrm{TiO}_{2} \cdot \mathrm{nH}_{2} \mathrm{O}$, obtained under industrial conditions.

\section{EXPERIMENTAL}

\section{Reagents}

A composition of titanyl sulfate solution obtained from Chemical Works „Police”, Poland, [wt\%]: $\mathrm{TiO}_{2}-10.79$, $\mathrm{Fe}^{2+}-2.68, \mathrm{Fe}^{3+}-0.15, \mathrm{H}_{2} \mathrm{SO}_{4}-20$.

A composition of hydrous titanium dioxide paste obtained from Chemical Works „Police”, Poland, [wt \%]: $\mathrm{TiO}_{2}-89.12, \mathrm{SO}_{3}-5.85$, moisture content-51.39 (determined in sample dried at $105^{\circ} \mathrm{C}$ ).

Hydrogen peroxide p.a., $30 \%$, $\mathrm{POCH}$, Poland.

Cobalt(II) sulfate hexahydrate p.a., POCH, Poland.

Sodium hydroxide p.a., $\mathrm{POCH}$, Poland.

Sulfuric acid p.a., 96\%, POCH, Poland.

\section{Experimental procedure}

A volume of titanyl sulfate solution in the range of from about 2 to $17 \mathrm{ml}$ was diluted with $100 \mathrm{ml}$ of $20 \mathrm{wt} \%$ $\mathrm{H}_{2} \mathrm{SO}_{4}$. When hydrous titanium dioxide paste was used as titanium source then a sample of about 2 to $6 \mathrm{~g}$ was dissolved in $50 \mathrm{ml}$ of boiling, concentrated sulfuric acid and diluted to $100 \mathrm{ml}$ with water. Next, $2 \mathrm{ml}$ of $30 \mathrm{wt} \%$ $\mathrm{H}_{2} \mathrm{O}_{2}$ was added to the prepared solution. Due to peroxide complex formation the color of the solution changed to dark red. Then a $50 \mathrm{ml}$ volume of $5 \mathrm{wt} \% \mathrm{CoSO}_{4}$ solution was added and the mixture was diluted to $400 \mathrm{ml}$ of water.

The proper amounts of titanium sources, corresponding to the required weight ratio of Ti:Co in starting solution, were given in Table 1. The weight ratios of Ti:Co equal to $0.41,0.81$ and 1.62 were controlled according to a stoichiometric composition of $\mathrm{Co}_{2} \mathrm{TiO}_{4}, \mathrm{CoTiO}_{3}$, and $\mathrm{CoTi}_{2} \mathrm{O}_{5}$, respectively. Some of the experiments were carried out also at non-stoichiometric weight ratios of Ti:Co equal to $0.18,0.2$ and 0.98 .

The starting mixture was placed in a three-necked flask provided with a stirrer, a reflux condenser, a dropping funnel and a $\mathrm{pH}$ measuring electrode. The precipitation was carried out with dropwise addition of $5 \mathrm{n}$ or $15 \mathrm{n} \mathrm{NaOH}$ solution. The more concentrated $\mathrm{NaOH}$ was used when hydrous titanium dioxide was the starting material. All experiments were carried out at continuous stirring over the period of $1 \mathrm{~h}$ at the temperature of $85^{\circ} \mathrm{C}$. The green suspension was formed at $\mathrm{pH}$ about 5 . The precipitating agent was added until the $\mathrm{pH}$ of $7-8$ was reached. It was necessary to achieve a high degree of conversion of the reactants. The precipitated solid substance was separated from the mother liquor and washed by decantation with hot distilled water. Next it was filtered out and dried in the oven to constant mass at $105^{\circ} \mathrm{C}$. After grinding in the ball mill the obtained powder was calcined at $900^{\circ} \mathrm{C}$ for $1 \mathrm{~h}$.

\section{Titration and instrumental methods}

The composition of the obtained powders was determined by titration methods. The solid samples were dissolved in boiling, concentrated hydrochloric acid, then the content of titanium, cobalt, and total iron was determined.

Determination of Ti(IV) was carried out by the volumetric method based on the reduction of Ti(IV) ions to Ti(III) with aluminium metal powder in an acidic solution. The next stage was the titration of this solution with ferric ammonium sulfate to the sharp color change from violet to red. As the indicator of the end-point the ammonium thiocyanate solution was used.

Determination of Co(II) was carried out with the complexometric method based on titration with ethylenediaminetetraacetic acid disodium salt in alkali solution. The used end-point indicator was murexide, changing color from orange to violet.

Determination of $\mathrm{Fe}(\mathrm{II})$ and total iron (after reduction of $\mathrm{Fe}$ (III) ions with stannous chloride) was carried out by titration of the solution with potassium dichromate using, as the end-point indicator, the sodium salt of diphenylaminosulfonic acid. The color change at the endpoint was from green to violet.

The phase composition of solid compounds was identified with the X-ray diffractometry on the Philips PW 1710 goniometer using $\mathrm{Cu} \mathrm{K} \alpha$ radiation at the voltage of $45 \mathrm{kV}$ and the $40 \mathrm{~mA}$ current.

\section{RESULTS AND DISSCUSSION}

It has been found that precipitation of green bodies takes place in the whole examined range of Ti:Co weight ratio from 0.18 to 1.62 . The precipitation is not affected by the presence of iron ions when the titanyl sulfate solution is used as titanium source, however iron is coprecipitated. Therefore, to obtain the cobalt titanate single phase using both, the titanyl sulfate solution containing iron ions and also hydrous titanium dioxide, different weight ratio of Ti:Co must be used. As it is shown in Table 1, the lower Ti:Co weight ratio is needed when the

Table 1. The conditions of cobalt titanates preparation and their elemental and phase composition

\begin{tabular}{|c|c|c|c|c|c|c|c|c|}
\hline \multirow{2}{*}{$\begin{array}{l}\text { Sample } \\
\text { code }\end{array}$} & \multirow{2}{*}{$\begin{array}{l}\text { Titanium } \\
\text { source }\end{array}$} & \multirow{2}{*}{$\begin{array}{l}\text { Amount of } \\
\text { titanium } \\
\text { source }\end{array}$} & \multirow{2}{*}{$\begin{array}{c}\text { Ti:Co } \\
\text { weight ratio } \\
\text { in starting solution }\end{array}$} & \multicolumn{3}{|c|}{$\begin{array}{l}\text { Elemental composition, wt \%, } \\
105^{\circ} \mathrm{C}\end{array}$} & \multirow{2}{*}{$\begin{array}{l}\Delta \mathrm{m}, \% \\
900^{\circ} \mathrm{C}\end{array}$} & \multirow[t]{2}{*}{ Phase composition $900^{\circ} \mathrm{C}$} \\
\hline & & & & $\mathrm{Ti}$ & Co & $\mathrm{Fe}$ & & \\
\hline Ti-Co1 & \multirow{5}{*}{$\begin{array}{l}\text { Titanyl } \\
\text { sulfate } \\
\text { solution }\end{array}$} & $1.87 \mathrm{ml}$ & 0.18 & 9.8 & 36.7 & 5.9 & 25.6 & $\mathrm{CO}_{2} \mathrm{TiO}_{4}$ \\
\hline Ti-Co2 & & $2.08 \mathrm{ml}$ & 0.20 & 12.5 & 28.8 & 7.7 & 25.5 & $\mathrm{CoTiO}_{3}+\mathrm{Co}_{2} \mathrm{TiO}_{4}$ \\
\hline Ti-Co3 & & $4.26 \mathrm{ml}$ & 0.41 & 18.3 & 25.0 & 8.2 & 21.6 & $\mathrm{CoTiO}_{3}+\mathrm{Co}_{2} \mathrm{TiO}_{4}$ \\
\hline Ti-Co4 & & $8.41 \mathrm{ml}$ & 0.81 & 21.8 & 21.2 & 9.4 & 19.8 & $\mathrm{CoTiO}_{3}$ \\
\hline Ti-Co5 & & $16.82 \mathrm{ml}$ & 1.62 & 25.0 & 14.8 & 12.5 & 8.5 & $\mathrm{CoTiO}_{3}+\mathrm{CoTi}_{2} \mathrm{O}_{5}$ \\
\hline Ti-Co6 & \multirow{5}{*}{$\begin{array}{c}\text { Hydrous } \\
\text { titanium } \\
\text { dioxide }\end{array}$} & $0.74 \mathrm{~g}$ & 0.20 & 17.4 & 38.4 & - & 22.1 & $\mathrm{Co}_{2} \mathrm{TiO}_{4}$ \\
\hline Ti-Co7 & & $1.52 \mathrm{~g}$ & 0.41 & 19.4 & 36.8 & - & 20.8 & $\mathrm{CoTiO}_{3}+\mathrm{Co}_{2} \mathrm{TiO}_{4}$ \\
\hline Ti-Co8 & & $3.00 \mathrm{~g}$ & 0.81 & 26.0 & 30.3 & - & 16.5 & $\mathrm{CoTiO}_{3}+\mathrm{Co}_{2} \mathrm{TiO}_{4}$ \\
\hline Ti-Co9 & & $3.63 \mathrm{~g}$ & 0.98 & 26.3 & 25.5 & - & 16.3 & $\mathrm{CoTiO}_{3}$ \\
\hline Ti-Co10 & & $5.99 \mathrm{~g}$ & 1.62 & 27.0 & 16.4 & - & 15.5 & $\mathrm{CoTiO}_{3}+\mathrm{TiO}_{2}$ \\
\hline
\end{tabular}




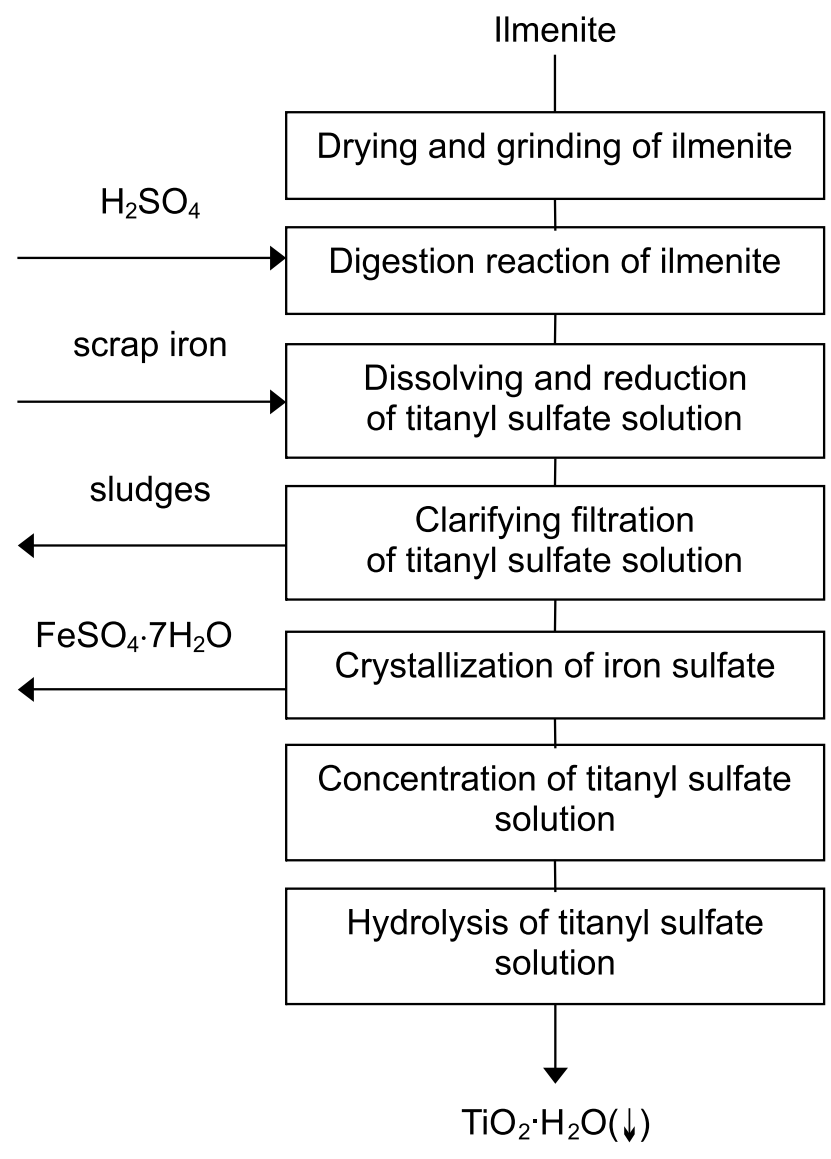

Figure 1. The block diagram of $\mathrm{TiOSO}_{4}$ and $\mathrm{TiO}_{2} \cdot \mathrm{H}_{2} \mathrm{O}$ preparation in the titanium dioxide technology titanyl sulfate solution is used. It is caused by the occurring in the solution $\mathrm{Fe}^{2+}$ ions which are oxidized to $\mathrm{Fe}^{3+}$ ions during the co-precipitation reaction and can substitute $\mathrm{Ti}^{4+}$ ions in the precipitate, due to similar ionic radii size. The determination of iron in dried samples confirmed that it occurs only in the +3 oxidation state. The presence of iron in the prepared materials have an influence on their color which changes from bluish green to brownish black in the case of $\mathrm{CoTiO}_{3}$ and from emerald green to black in the case of $\mathrm{Co}_{2} \mathrm{TiO}_{4}$.

The samples dried at $105^{\circ} \mathrm{C}$ are $\mathrm{X}$-ray amorphous. After their thermal treatment at $900^{\circ} \mathrm{C}$ for $1 \mathrm{~h}$ the crystalline phases of cobalt titanates are formed. It has been found that when the titanyl sulfate solution is used it is possible to obtain $\mathrm{Co}_{2} \mathrm{TiO}_{4}$ and $\mathrm{CoTiO}_{3}$ single phases at Ti:Co weight ratio equals 0.18 and 0.81 . When, the hydrous titanium dioxide is used as the reagent, the appropriate Ti:Co weight ratio is 0.2 and 0.98 , respectively. The results of diffractometric investigations are shown in Figure 2. The standard patterns of cobalt titanates shown at the bottom of the figure are taken from the ICPDS X-ray diffraction database. As it is shown in this figure, the samples containing iron preserve the same crystallographic structure as cobalt titanates without forming the additional phases originating from iron oxides like hematite. However, peak shifts can be observed due to the lattice distortion affected by the iron ions substitution. Figure 3 shows the most intense peak of Ti-Co1 and Ti-Co4 samples referred to the corresponding standard pattern of $\mathrm{Co}_{2} \mathrm{TiO}_{4}$ and $\mathrm{CoTiO}_{3}$. It is seen that peaks are shifted

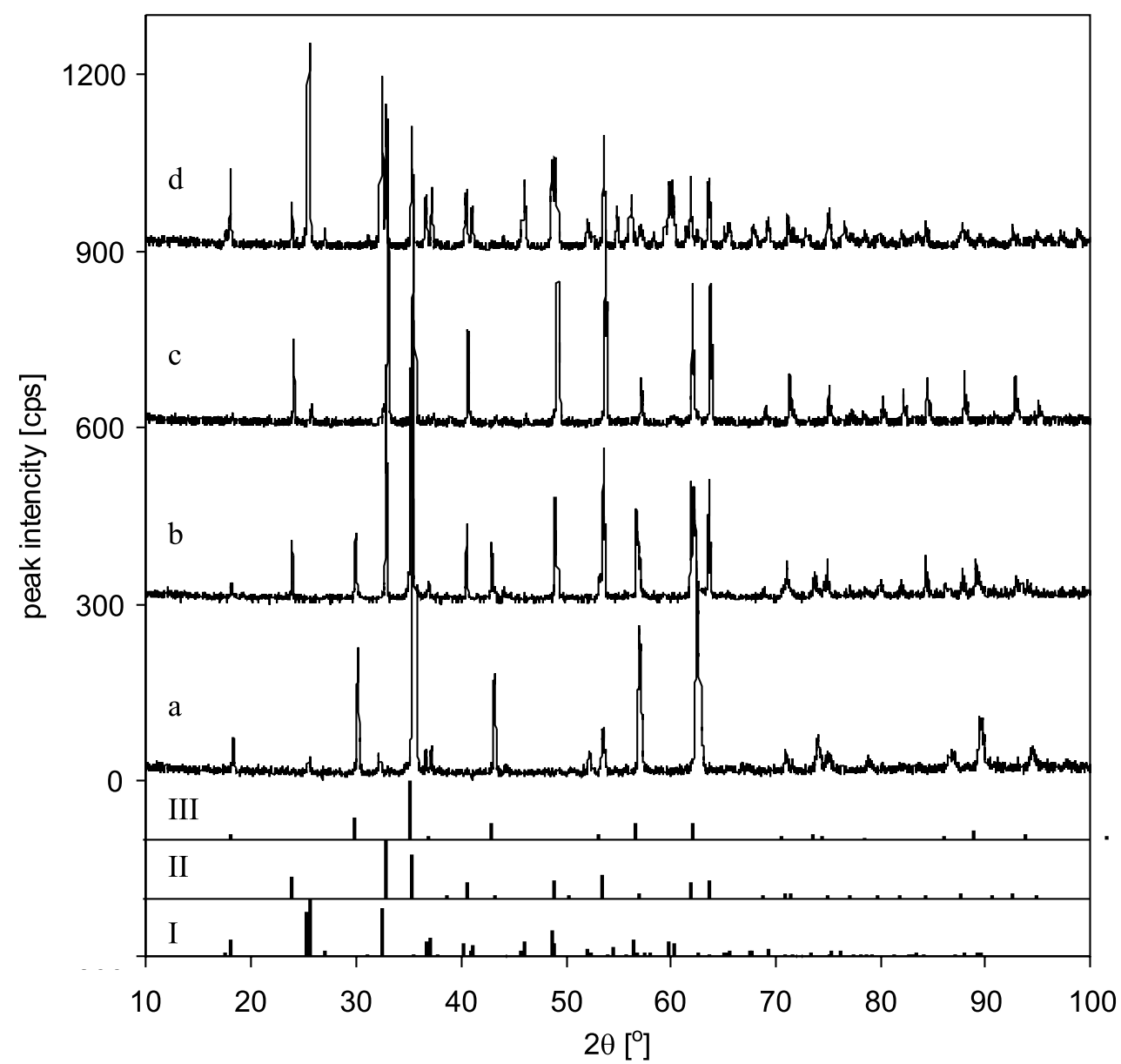

Figure 2. The diffraction patterns of the calcined samples and standard patterns of cobalt titanates: a-Ti-Co1, b-Ti-Co2, c-Ti$\mathrm{Co} 4$, d-Ti-Co5, I-CoTi ${ }_{2} \mathrm{O}_{5}, \mathrm{II}-\mathrm{CoTiO}_{3}, \mathrm{III}-\mathrm{Co}_{2} \mathrm{TiO}_{4}$ 
a)

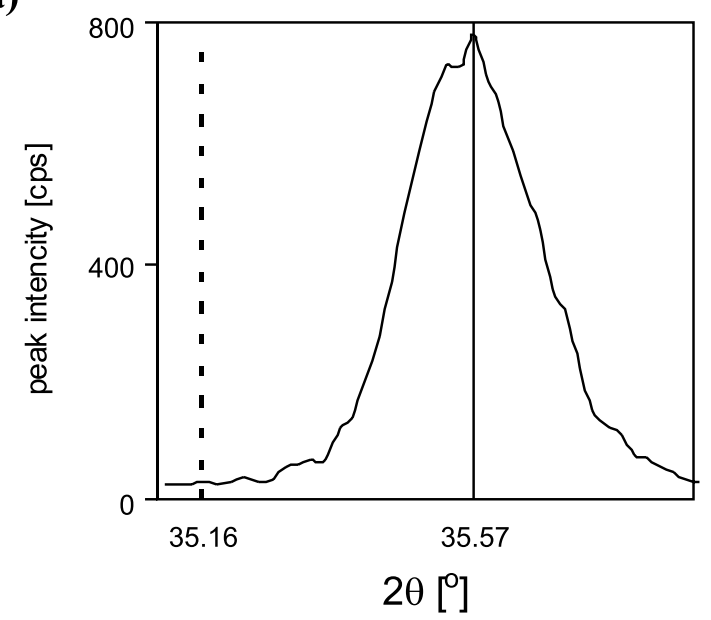

b)

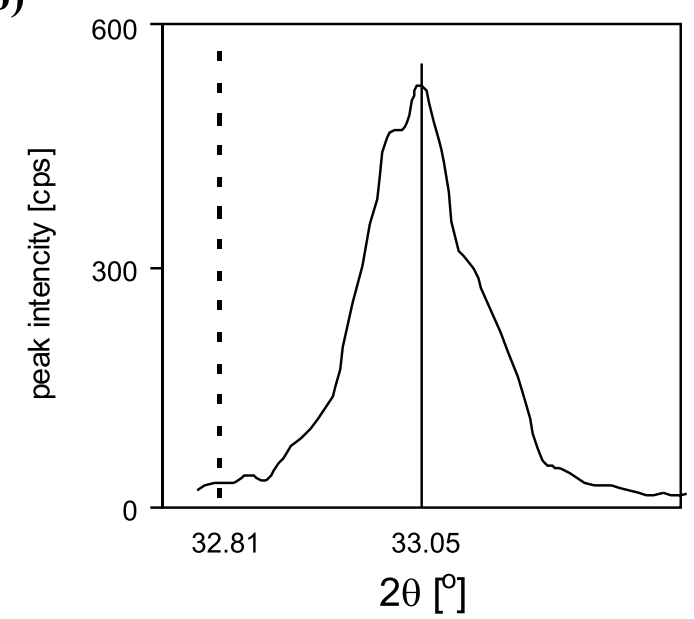

Figure 3. The most intense peak and corresponding standard pattern of: a) Ti-Co1 sample and $\mathrm{Co}_{2} \mathrm{TiO}_{4}$, b) Ti-Co4 sample and $\mathrm{CoTiO}_{3}$

towards higher $2 \theta$ value. This indicates a decrease of the unit cell volume of iron-doped samples.

\section{CONCLUSIONS}

The method of co-precipitation has been successfully applied to obtain the green bodies. Their thermal treatment at $900^{\circ} \mathrm{C}$ allowed to distinguish the crystalline single phases of $\mathrm{CoTiO}_{3}$ and $\mathrm{Co}_{2} \mathrm{TiO}_{4}$, in dependence on $\mathrm{Ti}: \mathrm{Co}$ weight ratio in the starting solution.

We have found that the intermediate products of ilmenite decomposition, originating from industrial conditions, are suitable for the preparation of cobalt titanates. In the case of the titanyl sulfate solution, used as titanium source, the obtained cobalt titanates contain from 5.9 to $12.5 \mathrm{wt} \%$ of $\mathrm{Fe}^{3+}$, which results in the darkening of their color. The iron containing samples can be applied as electrical materials. On the contrary, the samples prepared from the hydrous titanium dioxide, not containing iron, can be applied as pigments due to their intensive colors varying from emerald green to bluish green, in dependence on phase composition.

A series of experiments with other transition metals salts has been performed, using industrial titanium intermediate products and adopting the described method. We have stated that when, instead of cobalt sulfate solution, the solutions of $\mathrm{Ni}, \mathrm{Fe}, \mathrm{Zn}, \mathrm{Cu}$ and $\mathrm{Al}$ sulfates are used, then it is possible to obtain the corresponding metals titanates.

\section{LITERATURE CITED}

1. Yankin, A. M. \& Balakirev, V. F. (2002). Phase Equilibria in the Co-Mn-Ti-O System over Wide Ranges of Temperatures and Oxygen Pressures. Inorg. Mat. 38(4), 309 - 319. DOI: $10.1023 / \mathrm{A}: 1015150300878$.

2. Pacheco, F., Gonzalez, M., Medina, A., Velumani, S. \& Ascencio, J.A. (2004). Structural analysis of cobalt titanate nanoparticles obtained by sol-gel process. Appl. Phys. A: Mat. Sci. \& Proc. 78(4), 531 - 536. DOI: 10.1007/s00339-003-2454-4.

3. Zhou, L., Zhang, S., Cheng, J., Zhang, L. \& Zeng Z. (1997). Optical absorptions of nanoscaled $\mathrm{CoTiO}_{3}$ and $\mathrm{NiTiO}_{3}$. Mat. Sci. \& Eng. B. 49(2), 117 - 122. DOI: 10.1016/ S0921-5107(97)00115-3.

4. Pan, T.M., Lei, T.F. \& Chao T.S. (2001). Comparison of

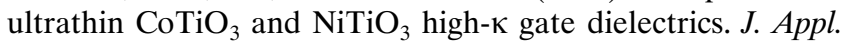
Phys. 89(6), 3447 - 3452. DOI: 10.1063/1.1347405.

5. Siemons, M. \& Simon, U. (2007). Gas sensing properties of volume-doped $\mathrm{CoTiO}_{3}$ synthesized via polyol method. Sens. Act.B. 126, 595 - 603. DOI: 10.1016/j.snb.2007.04.009.

6. Siemons, M. \& Simon U. (2006). Preparation and gas sensing properties of nanocrystalline La-doped $\mathrm{CoTiO}_{3}$. Sens. Act. B. 120, 110 - 118. DOI: 10.1016/j.snb.2006.01.049.

7. Chu, X., Liu, X., Wang, G. \& Meng, G. (1999). Preparation and gas-sensing properties of nano- $\mathrm{CoTiO}_{3}$. Mat. Res. Bull. 34(10/11), 1789 - 1795. DOI: 10.1016/S00255408(99)00167-1.

8. Levinson, R., Berdahl, P., Akbari, H. (2005). Solar spectral optical properties of pigments-Part II: survey of common colorants. Sol. Energy Mat. \& Sol. Cells. 89, 351 - 389. DOI: 10.1016/j.solmat.2004.11.013.

9. Othmer, K. (1983). Encyclopedia of chemical technology (Vol.23, pp. 113, 146, 153). A Wiley Interscience Publication, John Wiley \& Sons, New York.

10. Tsokov, P.D., Blaskov, V.N., Stefanov, Y. \& Dobrev T.M. (2006). Synthesis of cobalt titanates and their stability in sulphate solutions. J. Int. Res. Pub. 1, 22 - 30, from http:/ /www.ejournalnet.com/technomat/volume-1/technomat-1-3.swf

11. Pishch, I.V. \& Radion, E.V. (2003). Production of pigments with perovskite-like structure based on nickel titanate by the precipitation method. Glass and Ceramics. 60(5-6), 154 - 157. DOI: 10.1023/A:1025760901128.

12. Lin, Y., Chang, Y., Yang W. \& Tsai B. (2006). Synthesis and characterization of ilmenite $\mathrm{NiTiO}_{3}$ and $\mathrm{CoTiO}_{3}$ prepared by a modified Pechini method. J. Non-Crystal. Sol. 352(8), 789 - 794. DOI: 10.1016/j.jnoncrysol.2006.02.001.

13. Barksdale, J. (1996). Titanium: its occurrence, chemistry and technology (pp. 214). The Ronald Press Company, New York.

14. Charnet, T. (1999). Applied mineralogical studies on Australian sand ilmenite concentrate with special reference to its behaviour in the sulphate process. Min. Eng. 12(5), 485 - 495. DOI: 10.1016/S0892-6875(99)00035-7. 